\title{
Sistema de Informação dos Atendimentos da Coordenação de Apoio Pedagógico ao Discente
}

\author{
Marcos Vinícius Batista ${ }^{1}$, Yuri dos Reis ${ }^{2}$, Tharles de S. Andrade ${ }^{1}$, Elymar Pereira \\ Cabral $^{1}$, Renata Luiza da Costa ${ }^{1}$ \\ 'Departamento de Informática, Instituto Federal de Goiás (IFG) \\ Av. Universitária, s/n Vale das Goiabeiras - Inhumas - GO - Brazil \\ ${ }^{2}$ Departamento de Informática, Universidade Federal de Goiás (UFG) \\ Alameda Palmeiras, s/n - Câmpus Samambaia, Goiânia - GO - Brazil \\ \{viniciusbgds, irtharles\}@gmail.com, yuri-dosreis@hotmail.com, \\ \{elymar.cabral, renata.costa\}@ifg.edu.br
}

\begin{abstract}
This article describes the planning and implementation of a web system that aims to automate the recording of occurrences linked to the student service department. Currently, this job is done manually. For this reason, data flow needs better ways of managing information. This system is one of the projects of the Academic Software Factory of IFG, campus Inhumas. For the project and development of the system, we have used Astah Community tools, PHP language and MySQL Database, besides the use of development standards that the Factory adopts. The system is in the final stages of implementation.
\end{abstract}

Resumo. Este artigo descreve o planejamento e a implementação de um sistema web que tem como objetivo automatizar o registro de ocorrências ligadas ao departamento de atendimento ao discente. Atualmente, esse trabalho é feito manualmente. Por essa razão, o fluxo de dados carece de melhores formas de gestão da informação. Esse sistema é um dos projetos da Fábrica de Software acadêmica do IFG, câmpus Inhumas. Para o projeto e desenvolvimento do sistema, estão sendo utilizadas, principalmente, as ferramentas Astah Community, linguagem PHP e banco de dados MySQL, além do uso de padrões de desenvolvimento que a Fábrica adota. O sistema encontra-se em fase final de implementação.

\section{Introdução}

A Coordenação de Apoio Pedagógico ao Discente (CAPEDISC) é o departamento responsável por registrar ocorrências acadêmicas advindas de alunos e professores, visando auxiliar outros departamentos para que os resultados acadêmicos dos alunos sejam melhores. A CAPEDISC é responsável por receber e gerenciar diversos tipos de ocorrências que envolvam discentes (reclamação pelos professores, pelos alunos, problemas comportamentais, orientação psicológica, dependências em disciplinas, etc.).

As atribuições mencionadas são, atualmente, desenvolvidas por meio de controles manuais e planilhas eletrônicas. Contudo, entende-se que é preciso um sistema 
de informação para gerenciar, melhorar a segurança da informação, agilizar e dinamizar as atividades da CAPEDISC, pois, tal departamento ainda deve prestar contas de suas atividades e fazer acompanhamento das ocorrências ao longo do ano. Esta última atividade é difícil de ser conduzida manualmente quando o volume de informações é muito grande. Nesse sentido, a criação de um sistema WEB aparece como solução necessária para que os funcionários deste departamento tenham mais segurança e dinâmicidade em seus registros, tendo assim todas as vantagens que um sistema WEB traz. Assim, este texto apresenta o relato do desenvolvimento do sistema referente ao registro e controle de ocorrências do referido departamento.

\section{Projeto e desenvolvimento do software}

O desenvolvimento do sistema para a CAPEDISC foi iniciado pelo planejamento do mesmo, a partir da construção de um projeto. Foi adotado como orientação desse projeto, o paradigma da prototipação. Segundo Sommerville (2011), por meio da prototipação, pode-se melhorar a percepção do usuário em relação ao software. Dentro dessa orientação metodológica, destaca-se que este software está sendo desenvolvido como um dos projetos da Fábrica de Software Acadêmica do IFG câmpus Inhumas, seguindo assim, padrões de desenvolvimento específicos, baseados na engenharia de requisitos e documentação Práxis [Brito, Silva e Cabral 2013; Andrade, Costa e Cabral 2017]. Foram realizadas reuniões com os futuros usuários do sistema (Coordenador da CAPEDISC, assistente social, psicólogo, auxiliares do departamento), a fim de fazer o primeiro levantamento de requisitos para o protótipo.

Para determinar o fluxo de informações no sistema, a interação entre as funções e telas, dentre outras necessidades do sistema, foram utilizados diagramas da UML (Unified Modeling Language). O planejamento gráfico das telas, conforme padrão da Fábrica mencionada, foi desenvolvido por meio da ferramenta Pencil.

Com relação ao desenvolvimento, foram necessários conhecimentos em HTML, CSS, PHP, Javascript e, também, JQuery, além de MySQL. Ao longo do desenvolvimento, foram encontradas determinadas complicações, como, por exemplo, dúvidas relacionadas à conjugação da linguagem PHP com o banco de dados MySQL e o limite de alguns loops. Também foi possível, com o desenvolvimento do sistema, ter um contato com a fábrica de software que possibilitasse entender como funciona um sistema desde a sua documentação até a sua implementação, podendo assim aplicar os conhecimentos teóricos adquiridos no curso.

\section{Resultados}

Atualmente, o sistema encontra-se em fase final de desenvolvimento. A tela de cadastro de motivos de ocorrência (Figura 1) é de extrema importância, pois possibilita cadastro de motivos que não tenham sido previstos, ou seja, dá flexibilidade ao sistema. O sistema também conta com telas de consultas (Figuras 1 e 2). Ao exibir os resultados das consultas, o sistema possibilita alteração ou exclusão do registro. O sistema importa dados da base do IFG por meio de padrões da Fábrica de Software, o que evita redundância de dados e códigos, e contribui para desenvolvimento mais rápido e seguro. 


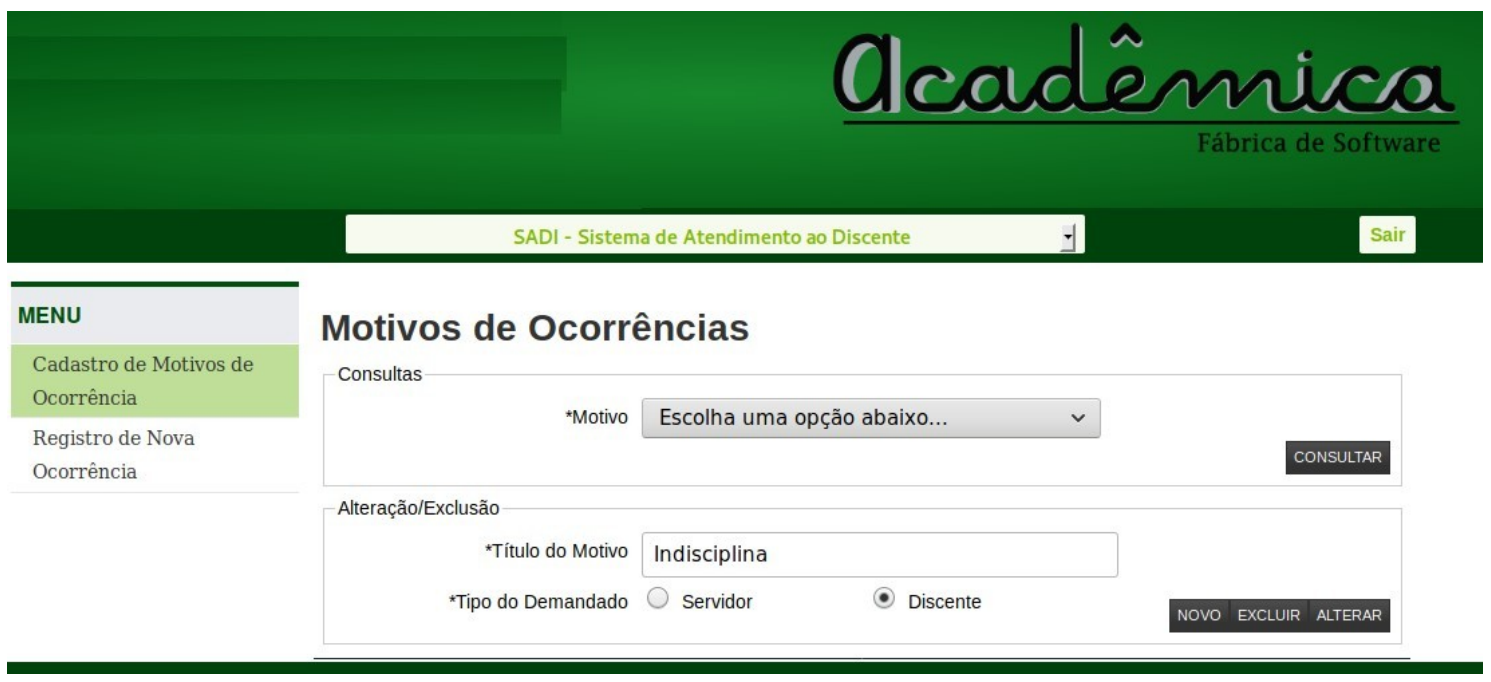

Figura 1. Tela para cadastrar motivos de ocorrências.

A implementação do sistema em questão, assim como os demais artefatos da FSW, tem como base o padrão MVC (Model View Controller) e a ADO, Advanced Data Objects, camada responsável pelas conexões com o banco de dados.

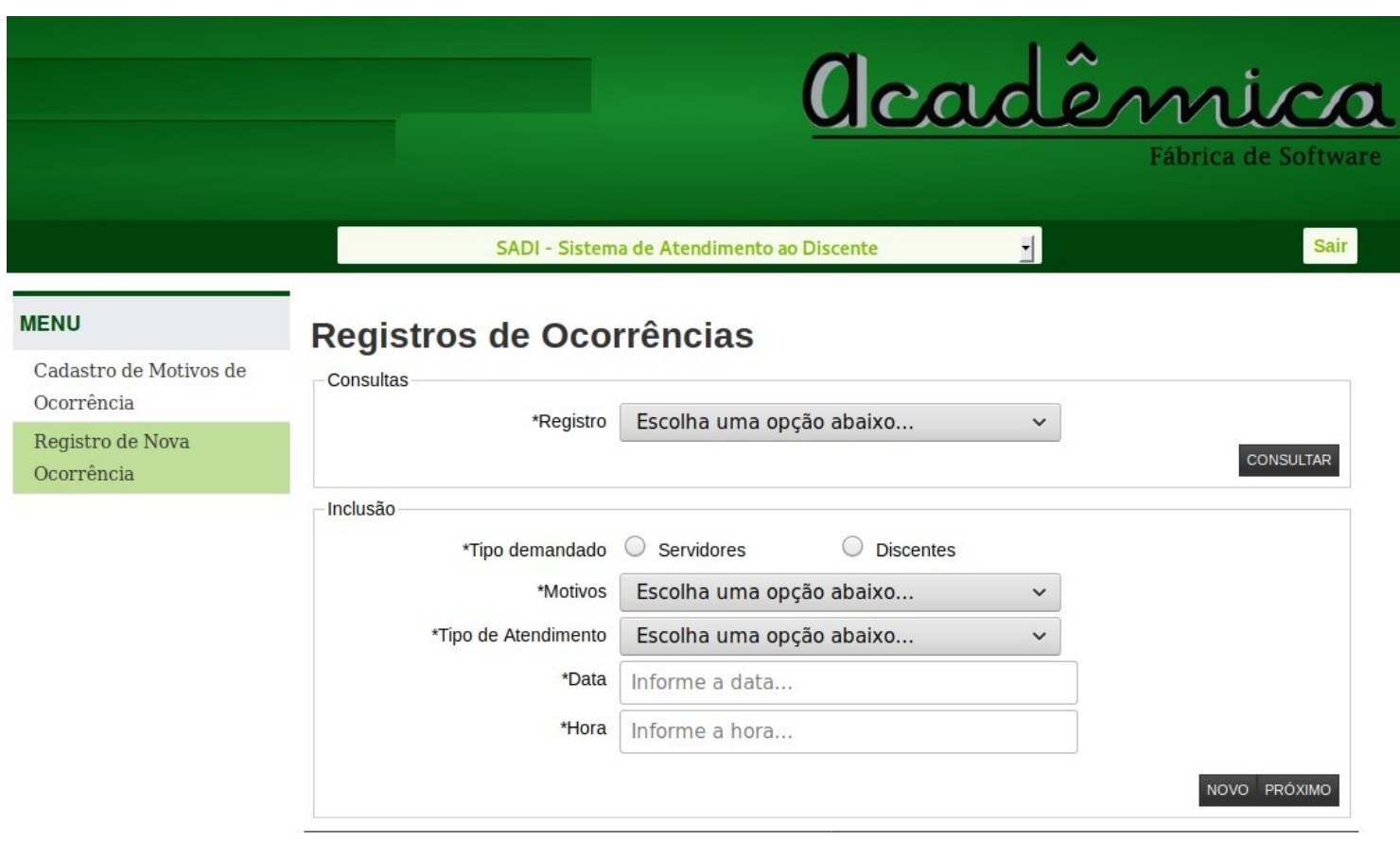

Figura 2. Tela para iniciar um registro de ocorrência.

Todos os sistemas da referida fábrica de softwares seguem a metodologia explicada por Brito, Silva e Cabral (2013). As ferramentas utilizadas são o Pencil, Bonita BPM, Astah Community, MySQL, PhpMyAdmin, Subversion (para controle de versões), Workbench, Apache 2, MySQL e as linguagens PHP, HTML5, CSS e JavaScript. Ademais, são empregados padrões de responsividade para as classes de interfaces. A Figura 3 mostra a tela principal do sistema em que é possível efetivar o registro da ocorrência: 


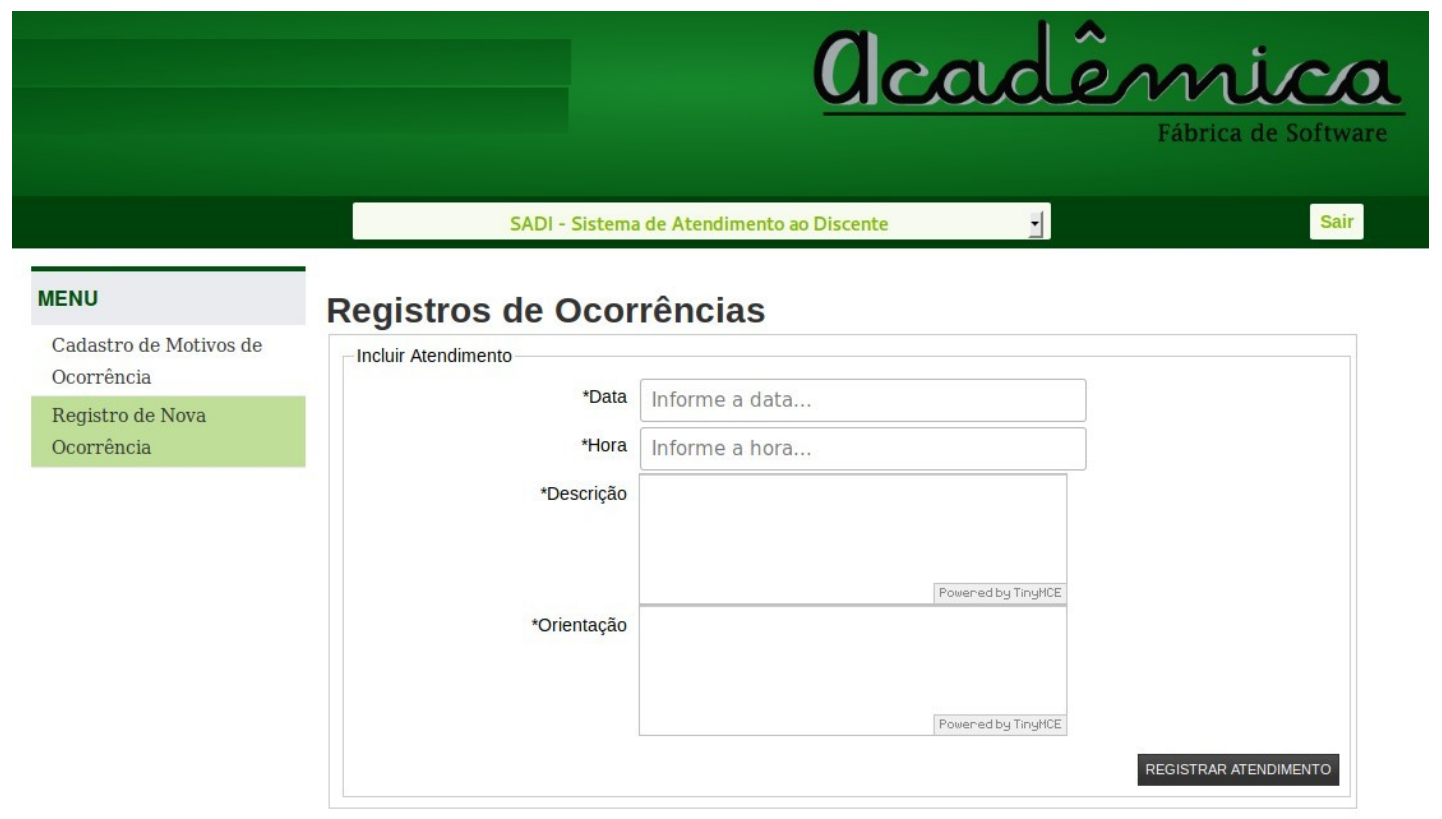

Figura 3. Tela para registrar atendimento.

O sistema oferece, ainda, a retirada de relatórios das ocorrências por períodos de tempo, por demandante e demandado.

\section{Conclusão}

A partir da apresentação do protótipo para os usuários principais do sistema, foi afirmado que tal versão atende às solicitações do departamento.

O sistema vem sendo desenvolvido há um ano e meio, por estudantes, de nível médio e superior, participantes da Fábrica de Software Acadêmica do câmpus Inhumas do IFG, sob orientação de professores vinculados. Observa-se que a contribuição é tanto para o IFG, que obtém avanços de informatização dos seus departamentos, como para os alunos. Concordando com Andrade, Costa e Cabral (2017 p. 1732), a metodologia da Fábrica "possibilita vivência integrada e prática das fases do processo de desenvolvimento de um sistema computacional”, além de o ambiente de trabalho proporcionar aos estudantes uma experiência muito próxima de um ambiente real de trabalho a respeito de habilidades interpessoais para o mercado profissional.

\section{Referências}

Andrade, T. de S., Costa, R. L., Cabral, E. P. (2017) “Metodologia de Desenvolvimento de Sistemas de uma Fábrica de Software Acadêmica: Estudo de Caso do Sistema para Controle de Jogos Olímpicos”. In Anais do XXVIII Simpósio Brasileiro de Informática na Educação (SBIE). Recife - PE, Brasil.

Brito, M. C. A., Silva, F. P., Cabral, E. P. (2013) "Elaboração de uma metodologia de desenvolvimento de software em uma instituição de ensino". In Revista Brasileira de Informática na Educação (RBIE), v. 21, n. 02, p. 52.

Sommerville, I. (2011) Engenharia de Software. 9a Edição. Editora Pearson Brasil. 